\title{
All-Learning: The state of the art of the models and the methodologies educational with ICT
}

\author{
Gabriel M. Ramirez ${ }^{\mathrm{a},}$, Cesar A. Collazos $^{\mathrm{a}}$, Fernando Moreira ${ }^{\mathrm{b}}$

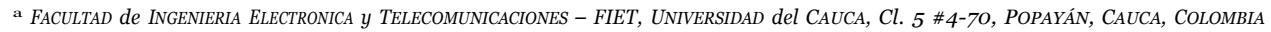 \\ b RESEARCH on Economics, MANAGEMENT AND INFORMATION Technologies - REMIT, Univ PORTUCALENSE, PORTUCALENSE Institute for LEGAL RESEARCH - IJP, \\ Univ Aveiro, IEETA, PORTUGAL
}

\section{A R T I C L E I N F O}

\section{Keywords:}

ICT

Model

Methodology

Integration

Education

\begin{abstract}
A B S T R A C T
This paper presents a systematic review of models and methodologies that integrate information and communication technologies (ICT) and education. The systematic review was based on the methodology of Kitchenham. The steps used and developed correspond to the steps proposed in the methodology. The starting point of the review are the research questions, then keywords, selection of the databases, definition of the inclusion and exclusion criteria, the definition of the search chains, search process and selection of papers, the analyzes of the paper and the results of the systematic review to answer the questions posed. In the systematic review, 919 papers were found in 6 academic databases and 129 relevant papers were selected. The work developed intends to know the di $\square$ erent models and methodologies that integrate the ICT and the education. Develop an analysis and characterize to find common elements among models and methodologies. The idea is to find limitations, disadvantages and spaces that allow to propose a new model. This systematic review is the first step in the development of a doctoral research in which the development of a U-Learning model based on Connective Learning and Experience Learning is proposed.
\end{abstract}

\section{Introduction}

There are currently di $\square$ erent media technologies that apply to education in order to develop learning processes mediated through information and communication technologies (ICT) such as electronic learning (e-learning), mobile learning (m-learning), game learning (g-learning) and Ubiquitous Learning (U-Learning), which have become an important support for current educational processes. Currently, an education without ICT is not conceivable due to the impact and permeability of technology in all environments and areas of society (Behera, 2013).

Whenever there are new ICT that may apply to education, is possible to develop new studies and research related to the impacts of technologies in educational processes (Zinny, 2015). U-Learning is learning that is done at any time, place, context and through any device (Gros et al., 2016a,b). This learning process makes use of ubiquity which is a very important characteristic and which imposes challenges that must be achieved with new research. It is necessary, to investigate how academic processes, pedagogical strategies, models and methodologies of education can be developed by using U-Learning. This concept opens up a broad spectrum of needs to develop new research that involves implementing ICT in Ubiquitous Learning (Gros et al., 2016a,b).

The systematic review is a literature search process to analyze, evaluate and interpret all relevant studies on a question or several 
research questions in a particular, specific area or phenomenon of interest (Kitchenham and Charters, 2007).

The methodology used includes the next stages: planning the review, developing the review and generating the reports of the review (Kitchenham and Charters, 2007). The paper is structured as follows: Section 2 explores the need for a systematic review in the area of the models that integrate the ICT and the models, methodologies and educational strategies. Section 3 presents the necessity of the review, Section 4 presents the methodology of the systematic review, the steps followed according to the methodology of Kitchenham (2012) and Petersen et al. (2008), research questions, keywords, chosen databases, inclusion and exclusion criteria, queries, the search process and the extraction of data, and data analysis and results. Section 5 indicates new specific review. Section 6 presents the results and discussions and Section 7 the conclusions and the future work.

\section{Topics of the paper}

The topics used in the systematic review are aimed at finding models that integrate educational methodologies in virtual education (Ramirez et al., 2017). There are di $\square$ erent models and methodologies that integrate technologies and educational methodologies in particular cases, so far, a general model has been found that integrates the di $\square$ erent methodologies focused on virtual education (Gros et al., 2016a,b). In accordance with this, it has been proposed to carry out the systematic review, in which interrelated models are sought that are referent to develop an integrated model. The topics that were used in the systematic review are models and educational methodologies integrated with ICT focused on education, such as e, m, U-learning (Martín et al., 2008).

The evolution of education through ICT, have been framed in learning through computers initially and with the emergence of the Internet, growth has been much greater. The internet has also evolved in a vertiginous form since its creation, the inclusion of the internet and ICT in education becomes a great contribution for the current and future education development. Nowadays yet its not possible to carry out educational processes without technology and more if they are oriented to the web (Ramírez and Collazos, 2016). Initially, e-learning focused on the web, followed by m-learning with the inclusion of mobile devices, then included the fundamentals of games in di $\square$ erent ways to give way to g-learning, also it tried to implement digital television with t-learning (Martín et al., 2008). U-Learning or ubiquitous learning is a concept that groups all ICT with the most important and relevant characteristics to the development of educational processes at any time, place, context and device (Gros et al., 2016a,b).

\section{Relevance of the review}

According to the World Bank's Learning for All (Cabrol and Székely, 2012), investment in people's knowledge and skills promotes the development of the world's population. One of the main goals of education at the global level has reduce the educational gap by bringing education to all people around the world (Willcox et al., 2016). The Inter-American Development Bank (IDB), Education for the 2012 Transformation, indicates that education must focus on quality, preparation for global scenarios and markets. Close the gap between education and the business world, it defines real needs and educate in skills to provide real solutionś (Cabrol and Székely, 2012).

The lack of investment in education and the traditional application of ICT in education have generated a slow evolution of it. This has led to a lag in education because while new students, mostly digital natives are moving towards an interconnected education with multiple elements and devices. The education continues to carry out educational processes aimed at digital migrant students (Oliveira et al., 2012). The needs of education for new students are di $\square$ erent and they need pedagogical and technological models, strategies, methodologies and updated technological paradigms, allowing to visualize the education of the future to apply it in the current education (Coto et al., 2016; Oliveira and Moreira, 2012).

Education is in a process of continuous change because the students learning needs are changing, the skills needed to develop jobs in companies have changed, the work and organizational profiles are di $\square$ erent (Willcox et al., 2016). The ICT in the companies have created the need for more specialized jobs, which has opened the door for new jobs and new professional activities. That are in fact making use of the technologies of information and communication (Hew and Kadir, 2016).

The possibility of finding new models and methodologies that integrate the strategies educative and technology of information and communication are an obvious necessity in the development of the education investigation. This aspect allows to know the previous works realized in the area and can be converted in reference framework for the development of the integration model proposed in the research.

\section{Systematic mapping review}

A systematic literature review is a method to analyze, evaluate and interpret all relevant studies to a particular research question, or specific area, or phenomenon of interest (Kitchenham, 2004). A systematic mapping review is a new version of this technique in which the evidence is represented in the results of the search and the analysis of data (Gros et al., 2016a,b). Kitchenham propose to use this methodology in the field of Software Engineering. The systematic review is a methodology that allows making searches of information in a rigorous way, allows to analyze, evaluate and interpret studies according to the specific research needs. In the systematic review, the methodology proposed by Kitchenham (2012).

This systematic review methodology has been selected because it has the necessary elements to carry out the search of information about the proposed topic. The importance of mapping the systematic review is found in the structure and steps it proposes to carry out the searches in an organized and methodological way which helps to generate reliable results in the investigations (Petersen et al., 2008). The process is detailed in Fig. 1. 


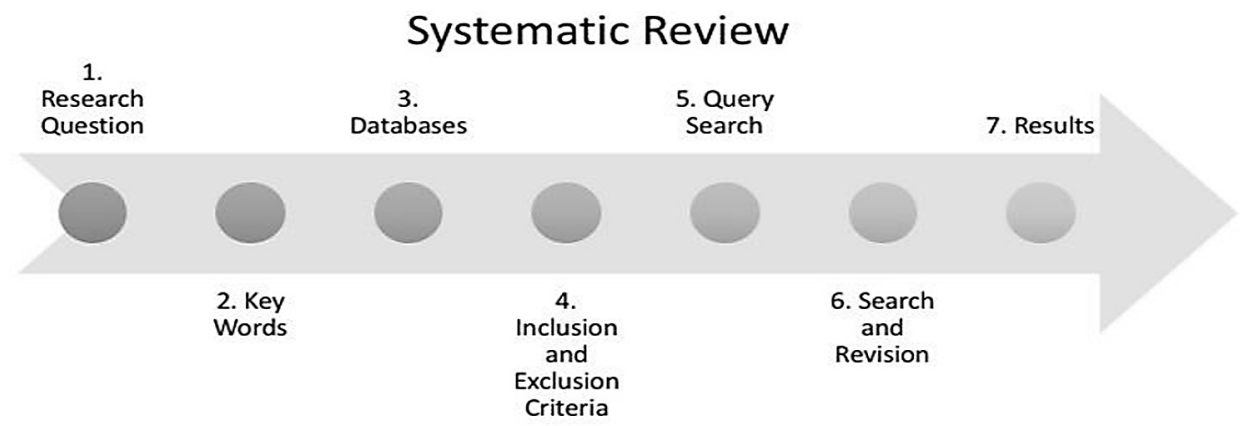

Fig. 1. Systematic review process.

In the systemic review process (Kitchenham and Charters, 2007), the following steps were followed: 1) two research questions were raised, 2) keywords were defined for searches in English, Portuguese and Spanish, 3) the databases to be consulted were defined, 4) the inclusion and exclusion criteria of papers were defined, as well as the range of time, 5) the advanced search strings were defined in each of the databases, 6) the process of search and revision of the papers were carried out, 7) new specific review, and 8) the results obtained in the review are presented.

\subsection{RESEARCH questions}

The purpose of this work was determined by the trends in information technologies applied to education and the need to update current educational models and methods to be applied in teaching processes from 2013 to 2016. Problems have been identified in the application of new information technologies in education because current learning processes do not adequately shape students' knowledge and skills in the workplace (Willcox et al., 2016). Accordingly, the following questions have been raised.

RQ1 What educational models have integrated educational methodologies and the new information and communications technologies ICT?

RQ2 What educational methodologies have been integrated models and information and communications technologies ICT?

In Fig. 2, the process of systematic review is graphically observed, the two questions are formulated together with the process of the revision making use of the methodology of Kitchenham and Charters (2007)) allow to obtain the results. This methodology indicates the step-by-step process in the systematic review.

\subsection{Definitions}

To have greater clarity in the terms used in the paper, a table of concepts definition was made. The concepts are related to the search strings used in the systematic review. Table 1 presents the concepts and their definitions.

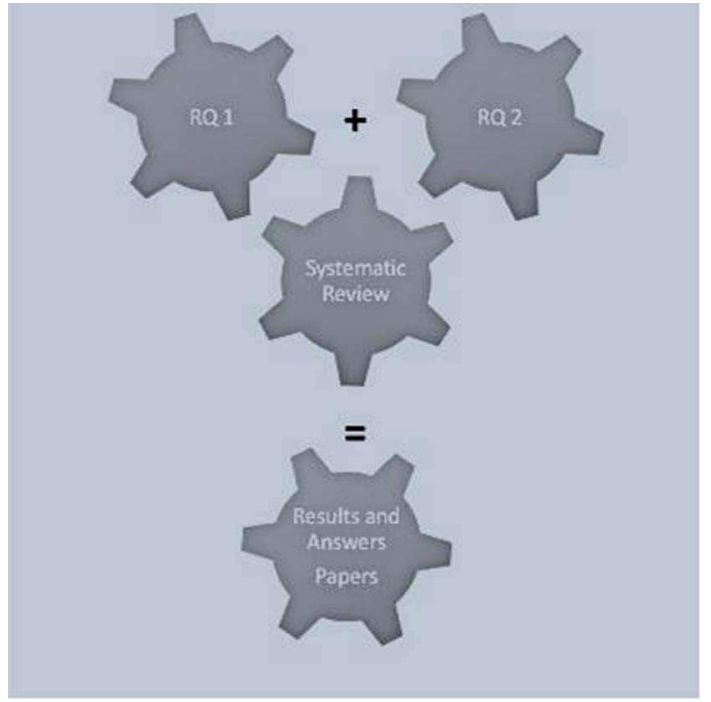

Fig. 2. Questions of the systematic review process. 
Table 1

Definition of general concepts.

\begin{tabular}{|c|c|}
\hline Word & Definition \\
\hline ICT & $\begin{array}{l}\text { Information and communications technology - or technologies is an umbrella term that includes any communication device or application, } \\
\text { encompassing: radio, television, cellular phones, computer and network hardware and software, satellite systems and so on, as well as the } \\
\text { various services and applications associated with them, such as videoconferencing and distance learning (Behera, 2013) }\end{array}$ \\
\hline U-Learning & U-Learning is the ubiquitous learning process that can be performed at any time, place, device and context (Gros et al., 2016a,b) \\
\hline M-Learning & $\begin{array}{l}\text { M-Learning or mobile learning is the learning process that is performed using mobile devices such as smart phones. Its main feature is mobility } \\
\text { (Martín et al., 2008) }\end{array}$ \\
\hline B-Learning & $\begin{array}{l}\text { B-Learning or Blended learning is a term increasingly used to describe the way e-learning is being combined with traditional classroom } \\
\text { methods and independent study (Martín et al., 2008) }\end{array}$ \\
\hline E-Learning & E-Learning or e-learning is the process of learning that is done using the internet and computers to access education (Behera, 2013) \\
\hline Model & $\begin{array}{l}\text { Graphical or verbal representation or simplified version of a concept, phenomenon, relationship, structure, system, or an aspect of the real } \\
\text { world. A representation of a system that allows for investigation of the properties of the system and, in some cases, prediction of future } \\
\text { outcomes (Frigg and Hartmann, 2006) }\end{array}$ \\
\hline Methodology & $\begin{array}{l}\text { A system of broad principles or rules from which specific methods or procedures may be derived to interpret and used to solve di } \square \text { erent } \\
\text { problems within the scope of a particular discipline (Kitchenham and Charters, 2007) }\end{array}$ \\
\hline
\end{tabular}

\subsection{Keywords}

For the systematic review, the search of 7 keywords in English, Spanish and Portuguese was defined, to include greater results of the searches and that allows having a more complete review in the databases. These words are detailed in Table 2.

\subsection{DATABASE}

We defined six (6) databases to perform the search for information according to the mapping of the systematic review. We chose these databases because they are the most internationally recognized in the area of engineering, computer science and education. These databases publish papers, conferences, book chapters and others. The databases are detailed in Table 3.

\subsection{Inclusion AND exclusion CRITERIA}

The inclusion and exclusion criteria of the mapping of the systematic review were defined according to the themes that are in the project and to the research questions for the searches.

The inclusion criteria are: 1) Papers published between the years 2013-2016, 2) Papers published in conferences, congresses, journals and book chapters, 3) Papers written in English, Portuguese and Spanish, 4) Papers that are found in the databases detailed in the table of databases, and 5) Papers related to higher education, virtual education, models and methodologies integrated with information and communication technologies.

The exclusion criteria are: 1) Document not available for download, 2) Papers in languages other than English, Spanish or Portuguese, 3) Papers that are not focused on the integration of educational methodologies with information and communication technologies, and 4) Gray literature.

Another criterion that should be applied is if the papers are duplicated in the databases or in the other databases.

Once the basic inclusion and exclusion criteria were applied, we proceed to review the titles and abstract of each of the papers. With the initial review, we decided if the paper is initially included in the accepted papers. After this process, each paper is reviewed in general form, to make reading the paper to know if it helps to answer the questions posed in the systematic review.

At the end of this process a review and detailed reading of the accepted papers are carried out and at this stage, it is defined if the paper is included definitively in the systematic revision.

Table 2

Keywords for the searches in the databases in English, Portuguese and Spanish.

\begin{tabular}{lll}
\hline Ingles & Portuguese & Español \\
\hline Methodology & Metodologia & Metodología \\
Model & Modelo & Modelo \\
Learning & Aprendizagem & Aprendizaje \\
ICT & ICT & TIC \\
Integrations & Integração & Integración \\
Education & Educação & Educación \\
Pedagogy & Pedagogia & Pedagogia \\
\hline
\end{tabular}


Table 3

Databases used in the search.

\begin{tabular}{lll}
\hline Name & Link & Acronym \\
\hline IEEE Xplore & http://ieeexplore.ieee.org/Xplore/home.jsp & IEEE Xplore \\
SCOPUS & http://www.scopus.com & SCOPUS \\
Science Direct & http://www.sciencedirect.com & Science Direct \\
ACM & http://dl.acm.org & ACM \\
Web of Science & https://webofknowledge.com & WOS \\
Google Scholar & https://scholar.google.com & GS \\
\hline
\end{tabular}

\subsection{Query SEARCH}

A general search string was defined based on the general concepts of the title of the search and that allowed answering the raised research questions. For each of the databases, we reviewed how to perform advanced searches and created the search string for each one of these, allowing more specific results according to the key words raised. It should be clarified that some databases are searched by abstract, title independently, therefore in some databases were created two or three search chains.

The result of the general query is as follows:

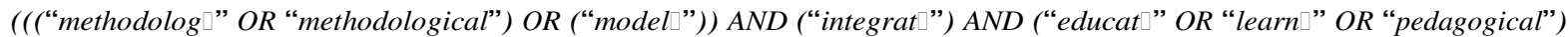
AND ("ICT" OR ("information" AND "communications" AND "technology")) AND (publication year > 2013))

\subsection{SEARCH process}

The search process is performed by accessing the six defined databases (IEEE, ACM, SCOPUS, Web of Science, Science Direct and Google Scholar), in each of the databases the specific string was defined to perform advanced searches, defined keywords and search criteria. We did not consider other studies or databases for the search, once the results obtained in each of the databases, we organized the data obtained in a general spreadsheet where all the data obtained from each one of the databases, was grouped by database and assigned a code to the database.

The information to organize the obtained information was the following: a) date of search, b) database code, c) database, d) search string, e) title, and f) abstract.

The systematic review mapping process was developed over a period of three months, starting in August and ending in October 2016. The information obtained allowed to classify the papers included in the revision into categories, to define the state of the art of the models, methodologies and strategies integrated with ICT.

\subsection{DATA EXTRACTION}

Once all the information of the searches in the databases is unified in the spreadsheet created, 919 items were found in the databases, the review process is initiated. Firstly, a general review is performed to find the papers, chapter of books, etc., 184 papers were repeated, and this is originated by the di $\square$ erent searches in the same databases by di $\square$ erent search chains.

Following this is a review of the titles and abstract of the papers, this review took into account the inclusion and exclusion criteria, all information relevant to the planned search and that will help to answer the research questions initially raised. The general summary of the accepted papers is detailed in Fig. 3.

The papers included in the mapping of the systematic review were 129, which met the inclusion criteria and are relevant to answer the initial questions of the systematic review. These papers belong to the defined databases. The general summary of accepted and rejected papers by databases is detailed in Fig. 4.

According to the information obtained in the mapping of the systematic review of papers obtained in the databases, 129 papers were accepted, 790 were not accepted and 184 papers were duplicated in the search results of the databases. The distribution of the papers according to the language in which it was written can be seen in Fig. 5.

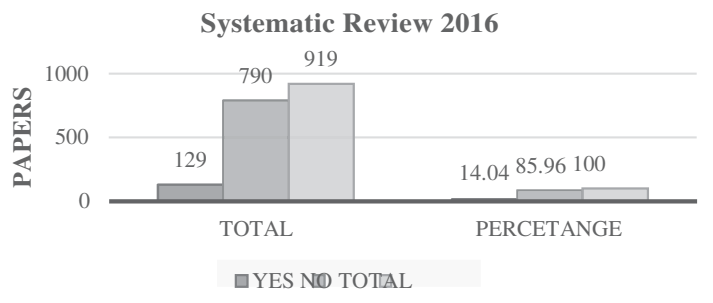

Fig. 3. Papers accepted in the systematic review. 
ACCEPTED PAPERS AND NOT

ACEPTED

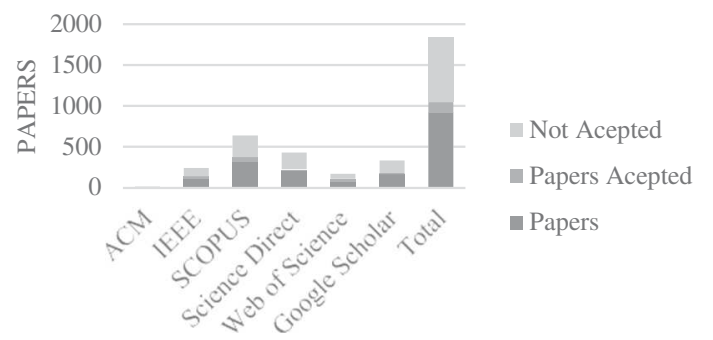

Fig. 4. Accepted and not accepted papers by database in the systematic review.

\section{LANGUAGE OF THE PAPERS}

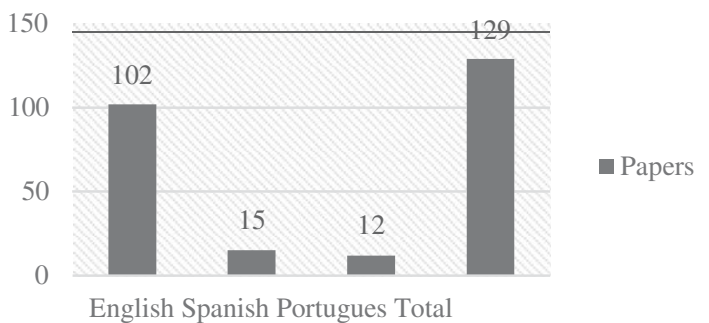

Fig. 5. Language of the papers accepted in the systematic review.

\subsection{DATA ANALYSIS AND results}

Based on the 129 accepted papers in the mapping of the systematic review, most of them were found in Scopus, Web of Science and IEEE databases were $90 \%$ of accepted papers are there. In the other databases (ACM, Science Direct and Google Scholar) is the remaining $10 \%$ of the systematic review (see Fig. 6).

In the mapping of the systematic review were classified according to the results obtained, according to this the classification is carried out in function of the topical models and methodologies integrated and the ICT. Table 4 presents the classification of papers.

The results obtained in the mapping of the systematic review allowed obtaining results related to the models, methodologies and strategies integrated with ICT. These results present a great variety of topics, according to the data, but representational area: Pedagogical 14\%, Higher Education 13\%, U-Learning 10\% and Technological pedagogical content knowledge (TPACK) Model 10\%, among others. The results are detailed in Fig. 7.

The papers found present di $\square$ erent models that have integrated ICT with education. In the review, we found interesting models such as the TPACK which is a model that identifies the types of knowledge in ICT that a teacher must have to impart the teaching process e $\square$ ectively. In this same sense we can see the combination of pedagogical strategies in higher education supported by ICT, as well as the integration of education technology with ICT through E-Learning, M-Learning and U-Learning (Herrera-Sánchez et al.. 2015).

Two interesting themes that are booming according to the revised papers is the Flip Classroom and the games applied to the Education or Gamification (Collazos et al., 2016).

The research questions of the systematic review present the results in the tables and figures above, and the answers to the

\section{Accepted Papers}

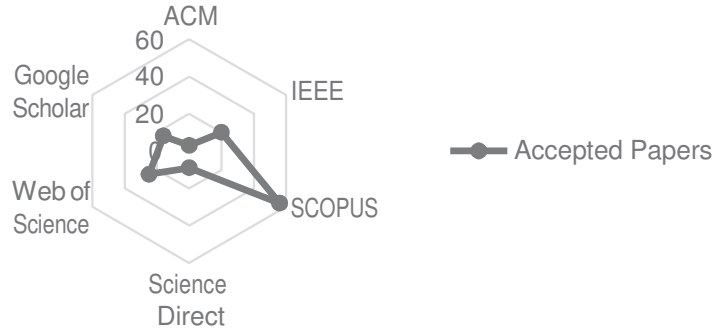

Fig. 6. Dispersion of the accepted papers. 
Table 4

Classification in the topical models, methodologies and ICT of the papers.

\begin{tabular}{llc}
\hline Topic & Papers & Percentage \\
\hline Integrated model & 38 & 29 \\
Integrated methodology & 20 & 16 \\
ICT & 71 & 55 \\
Total & 129 & 84
\end{tabular}

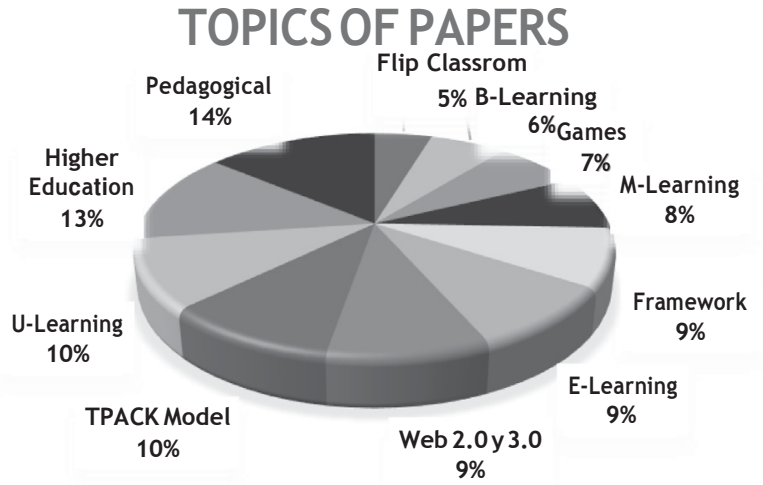

Fig. 7. Classifications of the topics papers.

questions guide the research of the doctoral project to develop a more specialized and specific systematic review. The models and methodologies related to $\mathrm{u}, \mathrm{m}, \mathrm{b}$, e-learning in the papers included in the systematic review indicate a relationship between ICT and the strategies and methodology of learning mediated through technology, Fig. 8 relations found.

The research questions initially raised in the systematic review are presented in the tables and figures above. The answers to the questions guide the research of the doctoral project to a new systematic review more specialized and specific. For each review question the answers were found.

RQ1 The models most important in the systematic review are: a) TPACK Model, b) Mobile Learning and Technology Acceptance Model TAM, c) A Maturity Model for Assessing the use of ICT, d) The eSG Project: A Blended Learning Model for Teaching Entrepreneurship Through Serious Games, Development of Instructional Model Base on Connectivism Learning, e) E-Inclusion Modeling for Blended, social ecological model analysis for ICT integration, f) Ubiquitous Learning: teaching modeling and simulation with technology, g) A cloud model for e $\square$ ective e-learning, innovate web 2.0 based collaborative learning and study circle model, a hierarchical model for e-learning implementation challenges using AHP and h) A conceptual framework for enhancing the motivation in an open learner model learning environment, the flipped classroom model at the university. The papers presented were the most relevant in terms of the models.

The paper allows us to understand the need to create models that integrate the new technologies of information and communication with educational processes. The most important contribution of the paper in the answer to the question is the di $\square$ erent ways found to integrate elements into educational models. These forms of integration are a framework for the U-Learning integrated model. The results obtained in the models contribute to solve the proposed research question.

The need to implement technologies in education is undeniable. In this sense, we have found very interesting models focused on

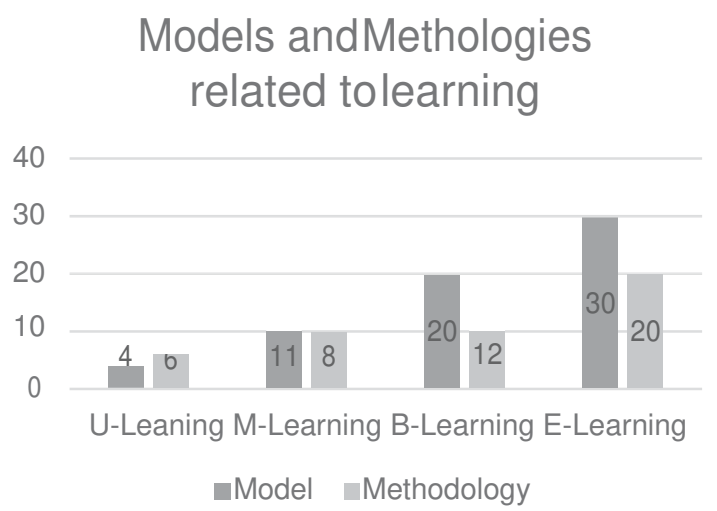

Fig. 8. Models and methodologies related to U, M, B, E-Learning in the papers. 
specific cases of education or focused on specific actors within educational processes. According to this, it is necessary to redefine and refine the new searches of the models, that is to say, one must search for a specific area of the search and clearly define the target for the research.

The papers found in the systematic review propose in the discussions to carry out more studies and applications that encompass new elements that allow to obtain more and better results that allow to evolve the proposed models the possibility of performing a new systematic revision focused on U-Learning and the relations with technological and pedagogical elements.

RQ2 The found methodologies most important in the systematic review are: a) An additional content development methodology in an adaptive agent based e-learning environment, b) The Evaluating of Integration of ICT in Higher Education: Foundation for a Methodology, c) Parallel virtual urban workshop: A 'reasonable-cost' methodology for academic internationalization in problemsolving oriented postgraduate subjects and Web 2.0 tools for role-play methodology in an undergraduate interdisciplinary environment. The papers presented were the most relevant in terms of the methodologies.

The significant contribution of the papers found with respect to the research question are focused on the approach of virtual education area, where the possibility of developing agents and environments adaptable to the educational means, the evaluation of the integrations with respect to the e $\square$ ectiveness of the educational process and the evaluation, as well as to the solution of problems in interdisciplinary environments. However, in the systematic review carried out, few papers were found that work on methodologies that integrate ICT and educational processes. The papers found and selected are those presented previously. According to this, few works are found to answer the question in a broader way.

\section{New specific review}

According to the results obtained in the systematic review, we considered the development of a new revision that will focus on working on the themes of U-Learning, Connective Learning and Learning Experiences, since they are the themes that will be taken on the basis of the proposed integration model in the research. In the new systematic review, also a search will take into account the topics of smart learning and deep learning for the pedagogical component within the framework of the theory of connective learning. In addition, a systematic review of existing tools that have U-Learning components and implement the xAPI standard will be carried out within the framework of the technological component (Vidal et al., 2015).

The new revision should focus on papers and studies related to U-Learning models integrated with connective learning. Taking into account that this topic is new and that the search was not found in a specific topic. It is proposed a new systematic re-view by separate words with synonyms and not with a complete query for the searches in the databases. The search by separate words generates more results and does not limit the results in the databases.

The words for the new systematic review mapping are directed to U-Learning, Connective Learning, Experience Learning and the synonyms of these words. It will use the same databases and the same languages in the new search.

Additionally, the new revision should focus only on the search of integrated models relating the above concepts. In this sense, it is proposed the construction of a U-Learning model and for this it is proposed the construction of a concept to a project, as well as to propose the relationships of this new concept with connective learning and experience learning. This will generate the framework and reference of the research project (Fullam and Langworthy, 2014).

\section{Results and discussions}

The systematic review and the results, indicate that in research in the area of ICT focused on education are in continuous changes, there is always the foolishness to find new ways of implementing technologies in educational ecosystems (Kang and Kim, 2015). As long as information and communication technologies evolve there will always be the possibility and need for research, where tests are performed and results that can be positive or not so positive. Education needs to be updated and modernized to educate students by providing tools that enable them to acquire the skills necessary to face the future in which they are to be developed (Moreira et al., 2016)

According, to the revision made it possible to observe the continuous development of researchers in applying di $\square$ erent technologies in education. It is understood by this that the process carried out is focused on the search and definition of elements that allow the development of an integrated methodologies and ICT model.

The review found many models that integrate ICT with education and methodologies with integrated models, but not all meet the inclusion criteria that were initially proposed, according to this models and methodologies included are the most relevant for the systematic revision.

In the reviewed papers and books, reference is made to apply the needs networks in education, the development of educational processes in multiple contexts, in di $\square$ erent spaces and at di $\square$ erent times, as well as the need to develop new pedagogical strategies and Improve the skills of teachers. Likewise, it is necessary to have a change in the skills and abilities of teachers, to redefine the roles of the educational actors in the educational processes, that is to say, the need for the revolution of education is implemented, im- plementing ICT as fundamental tools in the development and the evolution of future education (Gros et al., 2016a,b) .

In this sense, we believe that the systematic revision made is an important contribution in the search for information for the development of the base investigation to define the model U-Learning that is sought to create. 


\section{Conclusions and Further work}

The systematic review and selected papers are the first step in the construction of the state of the art of the model that is intended to be created in the doctoral research project. The purpose of the doctoral research is design an U-Learning model based on the experiences of learning and connective learning in virtual higher education (de Lima et al., 2015) and other authors that supports the U-learning are (Gros et al., 2016a,b). This first paper includes all the information relevant to the models, methodologies, strategies integrated with information and communication technologies, which are the basis of the integration model to be proposed in the ULearning model (Villa Martinez et al., 2010).

According to the systematic review, no model was found that generally indicates the guidelines of how to integrate information and communication technologies with education focused on integrate the models (Oliveira et al., 2012), just models, methodologies and strategies were found for specific cases but not a general model that integrates ICT and connective learning (Tumino and Adventista, 2016) and the principal author (Siemens et al., 2006) into U-Learning (Villa Martinez et al., 2010).

The new systematic review will be focus on the topics of U-Learning, Connective Learning and Learning Experiences (SerranoLaguna et al., 2016), since they are the themes that will be taken as the basis of the integration model proposed in the research (Kitchenham, 2012). The integration will be made based on the integrated models and methodologies that were found in the systematic review carried out.

The model that is planned to be designed will have as a technological basis the student's learning experiences from the technological perspective with the experience learning or standard xAPI (Manso-Vazquez et al., 2015) and from the pedagogical perspective will take into account the connective learning as a theory that supports the processes through information and communication technologies. It is important to take into account the acceptance of the educational processes of virtual education (Hew and Kadir, 2016), since in this case the revision focused on the search for integrated models and methodologies for this type of education.

From the pedagogical component of the project there are new proposals that must be reviewed and evaluated in the next systematic reviews that will be carried out within the framework of the project. In this sense, an interesting topic is the deep learning which works the theme of the changes of the Education, from the quality of teachers' skills, inclusion of ubiquitous technologies, students' abilities and the infinite possibility they have for learning with access to data and information through the web. The combination of these components is fundamental to develop new pedagogies and strategies that allow the evolution of educational processes (Fullam and Langworthy, 2014).

Authors like Gros et al. (2016a,b), Fullam and Langworthy (2014)) propose changes in pedagogical strategies that include ICT to generate a great change that allows to potentiate the development of educational processes and for this it must make use of learning in network. This aspect could be framed within the theory of connective learning and the development of learning processes at any time and place, in any context and through any device which is framed within the U-Learning. In this order of ideas, it is thought that a process of systematic revision is being developed according to the needs of the current education. However, it is necessary to delimit the technologies and models that are intended to be integrated, because it cannot be general in a general model, and what has been observed so far in the reviews is the integration of specific technologies and specific models, which indicates that the way forward is the definition of the models and technologies to be integrated in the model that plans to design.

\section{References}

Behera, S., 2013. E- and M-Learning : a comparative study. Int. J. New Trends Educ. Their Implications 65-78. Retrieved from http://www.ijonte.org/FileUpload/ ks63207/File/08.behera.pdf.

Cabrol, M., Székely, M., 2012. Educación para la transformación. Banco Interamericano de Desarrollo, Acosta, A., Blanco, R., Eroles, D., Goldberg, M. Retrieved from http://publications.iadb.org/handle/11319/392.

Collazos, Cesar. Jurado, Jose. Merchan, L., 2016. Entornos Ubicuos y Colaborativos (U-CSCL) para Ambientes de Enseñanza-Aprendizaje de Competencias Profesionales. Cali.

Coto, M., Collazos, C.a., Mora-Rivera, S., 2016. Modelo Colaborativo y Ubicuo para apoyar los procesos de enseñanza-aprendizaje a nivel Iberoamericano. Rev. Educ. Distancia (RED)(48). http://dx.doi.org/10.6018/red/48/10.

Frigg, S., Hartmann, R., 2006. Models in Science.

Fullam, M., Langworthy, M., 2014. A Rich Seam How New Pedagogies Find Deep Learning. Pearson. Retrieved from http://www.michaelfullan.ca/wp-content/ uploads/2014/01/3897.Rich Seam web.pdf.

Gros, B., Kinshuk, Maina, M., 2016a. The Future of Ubiquitous Learning: Learning Desings for Emerging Pedagogies. Lecture Notes in Educational Technology. The Future of ubiquitous Computing. Springer International Publishing. http://doi.org/10.1007/978-3-662-47724-3.

Gros, B., Kinshuk, Maina, M., 2016b. The Future of Ubiquitous Learning: Learning Desings for Emerging Pedagogies. Lecture Notes in Educational Technology. Springer International Publishing. http://doi.org/10.1007/978-3-662-47724-3.

Herrera-Sánchez, D., Gutierrez-Vela, F.L., Paderewski-Rodríguez, P., 2015. u-Learning Gamification : Gamificación aplicada a entornos ubicuos de enseñanza y aprendizaje. Congreso Iberoamericano de Ambientes de Aprendizaje Futuros (CIAAF'15), (September 2015), 12. Retrieved from https://www.researchgate.net/ publication/282647467_u-Learning_Gamification_Gamificacion_aplicada_a_entornos_ubicuos_de_ensenanza_y_aprendizaje.

Hew, T.-S., Kadir, S.L.S.A., 2016. Predicting the acceptance of cloud-based virtual learning environment: the roles of self determination and channel expansion theory. Telematics Inform. 33 (4), 990-1013. http://dx.doi.org/10.1016/j.tele.2016.01.004.

Kang, B.H., Kim, H., 2015. Proposal: a design of u-learning module application for multi-cultural students in Korea. Int. J. Softw. Eng. Appl. 9 (1), 167-172. http://doi. org/10.14257/ijseia.2015.9.1.14.

Kitchenham, B., 2004. Procedures for performing systematic reviews. Keele, UK, Keele University, 33(TR/SE-0401), 28. http://doi.org/10.1.1.122.3308.

Kitchenham, B.A., 2012. Systematic review in software engineering. IN: Proceedings of the 2nd International Workshop on Evidential Assessment of Software Technologies - EAST '12, (May), 1. http://dx doi.org/10.1145/2372233.2372235.

Kitchenham, B., Charters, S., 2007. Guidelines for performing systematic literature reviews in software engineering. Engineering 2, 1051. http://dx.doi.org/10.1145/ 1134285.1134500

de Lima, R.M., Guerra, L.T.B., Fiorin, A., 2015. Educação Ubíqua: Um Modelo de Adaptação para o Moodle. Revista Eletrônica Argentina-Brasil de Tecnologias Da Informação E Da Comunicação 1 (3). 
Manso-Vazquez, M., Caeiro-Rodriguez, M., Llamas-Nistal, M., 2015. XAPI-SRL: uses of an application profile for self-regulated learning based on the analysis of learning strategies. IEEE Front. Educ. Conf. (FIE) 2015, 1-8. http://dx.doi.org/10.1109/FIE.2015.7344049.

Martín, S., Gil, R., Díaz, G., Sancristobal, E., Castro, M., Peire, J., 2008. From e-learning to m-learning through b-learning and s-learning.

Moreira, F., Ferreira, M.J., Santos, C.P., Durão, N., 2016. Evolution and use of mobile devices in higher education: A case study in Portuguese Higher Education Institutions between 2009/2010 and 2014/2015. Telematics Inform. http://dx.doi.org/10.1016/j.tele.2016.08.010.

Oliveira, J.M., Rabello, S.A., Barbosa, J.L.V., Barbosa, D.N.F., 2012. Uma Infraestrutura Descentralizada para Ambientes de Aprendizagem Ubíqua. Rev. Bras. Inf. Educ. 20 (3), 85-99. http://dx.doi.org/10.5753/RBIE.2012.20.03.85.

Oliveira, L., Moreira, F., 2012. Personal Learning Systems Integration of web 2.0 applications and Content Management Systems. IN: Proceedings of ECKM 2010, The 11 th European Conference on Knowledge Management.

Petersen, Feldt, R., Mujtaba, S., Mattsson, M., 2008. Systematic Mapping Studies in Software Engineering.

Ramirez, G.M., Collazos, C.A., Moreira, F., 2017. A systematic mapping review of all-learning model of integration of educational methodologies in the ICT. In: Rocha, Á., Correia, A.M., Adeli, H., Reis, L.P., Costanzo, S. (Eds.), Recent Advances in Information Systems and Technologies, vol. 2, Springer International Publishing, Cham, pp. 897-907. http://dx.doi.org/10.1007/978-3-319-56538-5_89.

Ramírez, V.G.M., Collazos, O.C.A., 2016. Impacto de las herramientas Web 2.0 y 3.0 en los cursos virtuales de computación móvil y seguridad en aplicaciones móviles. In: 2016 IEEE 11th Colombian Computing Conference (CCC). http://dx.doi.org/10.1109/ColumbianCC.2016.7750795.

Serrano-Laguna, Á., Martínez-Ortiz, I., Haag, J., Regan, D., Johnson, A., Fernández-Manjón, B., 2016. Applying standards to systematize learning analytics in serious games. Comput. Stand. Interfaces, 50(June 2016), 16. http://dx.doi.org/10.1016/j.csi.2016.09.014.

Siemens, G., Onderwijsdagen, S., Age, D., Design, E., Siemens, G., Downes, S., Ellipsis Age, D., 2006. Connectivism : a new learning theory?

Tumino, M.C., Adventista, U., 2016. Conectivismo: Hacia El Nuevo Paradigma De La Enseñanza Por Competencias. Eur. Sci. J. 12 (10), 112-129. http://doi.org/10. 19044/esj.2016.v12n10p112.

Vidal, J.C., Rabelo, T., Lama, M., 2015. Semantic description of the Experience API Specification. http://doi.org/10.1109/ICALT.2015.128.

Villa Martinez, H.A., Tapia Moreno, F.J., Lopez Miranda, C.A., 2010. Aprendizaje ubicuo en la enseñanza de las matematicas. Revista Estudios Culturales, $123-136$. Retrieved from file:///C:/Users/JORGE/Downloads/Dialnet-AprendizajeUbicuoEnLaEnsenanzaDeLasMatematicas-3739983.pdf.

Willcox, K.E., Sarma, S., Lippel, P.H., 2016. Online education: a catalyst for higher education reforms, 39

Zinny, G.S., 2015. EDUCACION 3.0 (Norma). Bogota. 